\title{
SPOR KÜLTÜRÜNDE MİRAS AKTARIMI: ANKARA 19 MAYIS STADYUMU YIKIMI ÖRNEĞİ
}

\author{
Sevda KORKMAZ ${ }^{1}$ \\ 'İstanbul Büyükşehir Belediyesi Gençlik ve Spor Müdürlüğü
}

\begin{abstract}
Öz: Hayata geçirildiği zamanın siyasal ve kültürel iklimini yansıtan en önemli yapılardan bir tanesi, erken cumhuriyet dönemi için 19 Mayıs Stadyumu'dur. Cumhuriyetle birlikte yaşanan rejim değişikliğinin oluşturduğu fikri atmosferin mekânsal yansıma alanlarından birini oluşturan 19 Mayıs Stadyumu, cumhuriyetin taşıdığ 1 'yeni' değerleri dolaysız yansıtan, bu değerlerle yetișen nesillerin bir araya geldiği doğal bir mekan olmuş, erken cumhuriyet döneminde sayısız kutlama ve bayrama ev sahipliği yapmıştır. Bu makalede bugün yıkılıp yerine yeni bir stadyum yapılması kararı ile birlikte yeniden gündeme gelen 19 Mayıs Stadyumu örneği üzerinden spor kültürünün sürdürülebilir gelişiminde miras aktarımının yer ve varlık anlamının irdelenmesi amaçlanmıştır.
\end{abstract}

Anahtar Kelimeler: 19 Mayıs Stadyumu, Ankara, Spor Kültürü, Spor Mirası, Sürdürülebilirlik

\section{HERITAGE TRANSFER IN SPORTS CULTURE: THE DEMOLITION EXAMPLE OF ANKARA 19 MAY STADIUM}

\begin{abstract}
One of the most important structures that reflect the political and cultural climate of the time when it was built is the 19 Mayıs Stadyumu for the early republican era. The 19 Mayıs Stadyumu, which forms one of the spatial reflection areas of the intellectual atmosphere created by the regime which was emerged with the proclamation of Republic, has become a natural place where the generations of those who directly reflect the 'new' values carried by the Republic and grows up with these values, come together, and hosted numerous celebrations and festivals during the early republican period. In this article, it is aimed to examine the meaning of place and entity of the transfer of heritage in the sustainable development of sports cultures through the example of 19 Mayıs Stadyumu, which has become a current issue with the decision of building a new stadium by pulling down it.
\end{abstract}

Key Words: 19 Mayıs Stadyumu, Ankara, Sport Culture, Sport Heritage, Sustainability

\section{GíRis}

Bir ülke veya şehirdeki yapılar, inşa edildiği yerin ve dönemin sosyal, kültürel ve siyasi iklimini belgeleyen unsurlar olarak değerlendirilmekte (Korkmaz, 2007), o toplumun miras1 arasında yer almaktadır. Mirası oluşturan diğer tüm unsurlar gibi spor alanları ve spor yapıları da yapıldığı dönemin eğilimleri, yönelimleri, öncelikleri kısacası toplumsal atmosferinin yansımasını oluşturmaktadır. Bugünlerde yıkımı ile gündeme gelen 19 Mayıs Stadyumu da erken cumhuriyet dönemi spor mirası arasında yer almaktadır. Stadyumun öyküsüne geçmeden önce kültürün bir parçası olarak spor ve spor mirası ile kültürel miras kavramları üzerinde biraz durmak, konunun çerçevesini daha iyi ortaya koymak açısından yardımcı olacaktır.

'Kültür' kelimesinin kökü tarımda gelişimden ikamet etmeye, tapmaktan korunmaya kadar birçok anlama gelen Latince colere kelimesinden gelmektedir. Kültür hem düzenlemeye hem kendiliğinden büyümeye, gelişmeye işaret etmektedir. Kültürel olan değiștirilebilendir ${ }^{1}$ (Eagleton, 2005). Kültürel miras kavramı ise ilk olarak UNESCO'nun 1972 genel konferansında benimsenen sözleşmede kullanılmıştır. Kültürel miras bir gruba veya topluma

\footnotetext{
${ }^{1}$ Detaylı okuma için bkz. Terry Eagleton, Kültür Yorumları. Çev. Özge Çelik. İstanbul: Ayrıntı Yayınları.
} 
ait önceki kuşaklardan miras kalan, halen korunan ve yararlanmaları için gelecek kuşaklara bırakılan fiziksel eserler ve somut olmayan özelliklerdir (Tonta, 2014). Kültürel mirasın ne olduğu mimarlık mirası, arkeolojik miras, taşınabilir kültürel (nesneler) miras, maddi olmayan kültürel miras vb alt öğelere ayrılarak somuta indirgenmektedir (Tekeli, 2003). Henson (2004) çalışmasında geçmiş, tarih ve miras olgularını tanımlayan unsurları ve öğrenme sürecinde kullanılabilecek yöntemleri şöyle bir tablo haline getirmiştir (Henson 2004'ten akt. Yeşilbursa, 2011);

Geçmiş, Tarih ve Miras Olguları ve Öğrenme Yöntemleri

\begin{tabular}{|c|c|c|}
\hline Geçmiş & Tarih & Miras \\
\hline $\begin{array}{l}\text { Fiziksel kalıntılar-sitler, objeler, } \\
\text { el yazmaları, resimler vb. }\end{array}$ & $\begin{array}{l}\text { Olayların veya dönemlerin } \\
\text { yorumlarını yapmak, tekrar } \\
\text { oluşturma. }\end{array}$ & $\begin{array}{l}\text { Miras yerleri, el ürünleri ve } \\
\text { obje koleksiyonlar1, tarihi } \\
\text { mitler. }\end{array}$ \\
\hline \multicolumn{3}{|c|}{ Yukarıdaki olgular aşağıdaki süreçlerle işlerlik kazanır: } \\
\hline $\begin{array}{l}\text { Kanıtları toplamak (araştırma, } \\
\text { kazı yapmak) }\end{array}$ & $\begin{array}{l}\text { Kaniti yorumlamak (kronoloji, } \\
\text { yorumlama metodu, siralama) }\end{array}$ & $\begin{array}{l}\text { Tarihi ürünler oluşturmak } \\
\text { (Geçmiş: sitenin tekrar bir } \\
\text { yorumunu oluşturmak. } \\
\text { Tarih: sitenin insan-yer } \\
\text { etkileşiminin sembolü olarak } \\
\text { benimsenmesi }\end{array}$ \\
\hline \multicolumn{3}{|c|}{ Yukarıdaki süreçler aşağıdaki öğrenme tipleri için kullanılabilir: } \\
\hline $\begin{array}{lr}\text { Geçmişin olguları hakkında } \\
\text { öğrenmek (sitenin nası } \\
\text { yapıldığını anlamaya çalışmak, } \\
\text { fiziksel } \\
\text { tanımlamaya çalışmak) }\end{array}$ & $\begin{array}{l}\text { Geçmişin izlerinden } \\
\text { olgularından öğrenmek }\end{array}$ & $\begin{array}{l}\text { Tarihimizi ve geçmişimizi keyif } \\
\text { almak, yararlanmak ya da } \\
\text { günümüzü doğrulamak için } \\
\text { kullanmayı öğrenmek }\end{array}$ \\
\hline
\end{tabular}

Her ne kadar miras kavramı geçmişten günümüze kalan unsurları içerse de Tekeli’ye göre temel sorun, kültürel miras ile değişmenin ilişsisinin nasıl kurulacağıdır. Tekeli (2003), soruna cevabın koruma merkezli söylemin yerine sürdürülebilirlik ${ }^{2}$ merkezli bir söylemin geçmesinin olduğunu belirtmektedir. Spor alanındaki sürdürülebilirliğe dair çalışmalarında ${ }^{3}$ Koçak ve arkadaşları (2013) belirledikleri 6 boyut içerisinde spor kültürü sosyal sürdürülebilirlik boyutunda alt tema olarak yer almaktadır. Spora katılımın desteklenmesi boyutu ise sporun kültür olarak benimsenmesi ve yayılması noktasında önemli işlevleri yerine getirmektedir.

Toplumun devamında, kültürlerinin korunması, kendilerini geliştirebilmeleri için başka yöntem, metot ve araçlar olduğu kadar spor ve sportif faaliyetler (Koçak ve ark., 2013) diğer bir ifadeyle kültürün tüm öğelerinin olduğu gibi spor da etkili olmaktadır. Bu anlamda her biri ayrı katkılar sunan ve miraslar oluşturan öğelerin toplamı, sürdürülebilir gelişim için büyük önem taşımaktadır.

Son yıllarda kültürel mirasa erişim, kültürel mirasın korunması yorumlanması ve yönetimi olarak tanımlanan miras bilimi isminde bir bilim dalı ortaya çıkmıştır (Tonta, 2014). Miras

\footnotetext{
${ }^{2}$ Sürdürülebilirlik kavramı, 1987 Bruthland Raporu olarak da tanınan Ortak Geleceğimiz raporunda geliştirilmiş ve daha sonra 1992 'de Rio Çevre ve Kalkınma Konferansıyla evrensel olarak benimsenen bir ilke haline gelmiştir. Sürdürülebilir kalkınma, "bugünün ihtiyaçlarını, gelecek kuşakların da kendi kalkınma ihtiyaçlarını karşılayabilme olanağından ödün vermeden karşılamak”tır (Tekeli, 2003).

3 Sporda sürdürülebilirliğin kapsamına dair detaylı okuma için bakınız: Koçak vd. (2013). Sporda sürdürülebilirliğin boyutlarının belirlenmesi. Ankara Üniversitesi Spor Bilimleri Fakültesi Dergisi. 11(2):113129.
} 
çalışmaları içerisinde spor mirası araştırmaları yeni yeni gelişen bir alanı oluşturmaktadır. Bugünün kaynağı olarak spor mirası, stadyum dizaynından çağdaş spor uygulamalarını meşrulaştırmaya ve kutsamaya/anmaya kadar her şeyde kullanılmıştır, kullanılmaktadır (Ramshaw, 2011). Ramshaw ve Gammon (2005) spor mirasının açıkça tanımlanmış dört kategoriye yerleştirildiğinde daha iyi anlaşılacağını öne sürmektedir;

Spor Mirası Türleri

\begin{tabular}{|l|l|l|l|}
\hline Somut Taşınmaz & Somut Taşınır & Somut Olmayan & $\begin{array}{l}\text { Spor Mirası Bileşeni Teşhir Eden } \\
\text { Ürün ve Hizmetler }\end{array}$ \\
\hline $\begin{array}{l}\text { Geçmişle bağı } \\
\text { olan yerler, } \\
\text { mekanlar }\end{array}$ & $\begin{array}{l}\text { Objeler, eşyalar, } \\
\text { somut } \\
\text { deneyimler }\end{array}$ & $\begin{array}{l}\text { Ritüeller, gelenekler, } \\
\text { tezahüratlar, anılar, elle } \\
\text { tutulmayan diğer öğeler }\end{array}$ & $\begin{array}{l}\text { Miras unsuruna sahip reprodüksiyon } \\
\text { spor ürünleri ve hizmetler }\end{array}$ \\
\hline
\end{tabular}

Ramshaw ve Gammon'un bu tanımlamasına dayanarak makalemizin konusunu oluşturan 19 Mayıs Stadyumu'nun somut taşınmaz spor mirası kapsamına girdiğini söylemek mümkündür. Gerçekten de stadyumların toplumsal yaşamımızda önemli bir yeri bulunmaktadır. Geçmişte de günümüzde de barındırdıkları spor ve diğer farklı etkinlikler dolayısıyla toplumsal yaşamın merkezinde yer alan stadyumlar, kitlesel kullanımları dolayısıyla bir yandan kentsel altyapı ve donatının zorunlu bileşeni olurken diğer yandan kent peyzajının kimliğini ve niteliğini belirlemektedir. Ayrıca yapısal büyüklükleri sebebiyle kentsel peyzaja egemen konumları kentin fiziksel ve zihinsel haritasında referans oluşturmaktadır. Bu nitelikleriyle diğer spor yapılarından ayrılan stadyumlar, kentsel dönüşüm ve gelişimin odağı ve itici gücüdürler. Her dönemde gündelik yaşamın parçası olan stadyumlar, spora yönelik işlevleri yanı sıra sosyoekonomik ve sosyo-kültürel erke yönelik simgesel anlamlarıyla da öne çıkmaktadır (Aksu, 2011). 19 Mayıs Stadyumu da inşa edildiği Erken Cumhuriyet Dönemi'nin fikri atmosferinin mekansal karşılığı niteliğiyle cumhuriyetin simge yapılarından biridir. Zamanla işlevini ve önemini yitiren Stadyumu korumak ve önemini vurgulamak için Ankara Mimarlar Odası Şubesi direnirken, Gençlik ve Spor Genel Müdürlüğü yıkıp yerine yapılacak 'modern' yapı ile kentin stadyum ihtiyacını karşılamak istemektedir. Çalışmamızın devamında stadın yapım ve inşa öyküsü üzerinden spor kültürünün gelişimi ve sürdürülebilirliği noktasında spor mirasının yerine değinilecektir.

Stadyum, uzun yıllar boyunca oldukça bayram, tören vb etkinliklere mekan olarak ev sahipliği yaparak bu etkinliklere katılanların yaşamlarında ayrı bir yer edindiği gibi, erken cumhuriyet döneminden günümüze ülkemiz için oldukça yeni olan pek çok spor branşının ilk maçları, şampiyona ve turnuvalarına şahitlik etmiştir. Bu kadar çok ilklere sahne olmuş, yapım ve inşa süreci hikayesi ile farklı ve özellikli bir yeri olan Türkiye'nin ilk stadyumu örneği üzerinden spor mirasının sonraki nesillere aktarımı ile spor kültürünün sürdürülebilirliği arasındaki doğru orantı incelenmeye çalışılmıştır.

\section{YÖNTEM}

Bu çalışmada bugünlerde yıkılma haberleri ile gündeme gelen yapım ve inşa süreci, spor mirası olarak değeriyle 19 Mayıs Stadyumu örneği üzerinden spor kültürünün sürdürülebilir gelişimi noktasında spor mirasının korunması konusu tarihsel sosyolojik bakış açısıyla irdelenmiştir. Makalede, araştırma konusu gereği çok sayıda çalışmanın incelenmesi, derlenmesi, tasnif edilmesi ve sentez edilmesini olanaklı kılan literatür tarama (Demirci, 2014; Keser, http://kisi.deu.edu.tr) ile araştırılan konuyla ilgili bilgi içeren yazılı materyallerin bulunması, incelenmesi, sentezlenmesi için düzenlenmesinin yapılarak analizini kapsayan doküman incelemesi (Karasar, 2007; Yıldırım ve Şimşek, 2006) yöntemleri kullanılarak bulgular derlenmiştir. 


\section{BULGULAR}

\section{Düşünce aşaması}

Erken cumhuriyet döneminde mimarlık, Cumhuriyet'in gerçekleştirmek istediği modernleşme projesinin biçimsel karşılığı olarak kullanılmıştır. Devrime biçim vermek olarak tanımlanabilen inkılâp mimarisi anlayışında yeni yapılar, biçimin içeriği değiştirebileceği varsayımı ve temsil gücüne duyulan inançla birlikte inşa edilmiştir (Bozdoğan, 2015). Devrim ilkelerini hayata taşımaya dönük tasarlanan mekânları içeren planlı ve kapsamlı imar çalışmaları, Cumhuriyetin ilanı sonrası başkent olan Ankara'nın diğer şehirlere model ${ }^{4}$ olması hedefiyle hayata geçirilmiştir. Şehirlere verilmek istenen çağdaşlaşma öğeleri ve biçimi, bu şehirlerin ve mekânların kullanımı yoluyla bireylere aktarılmak istenmiştir.

Modern yaşamın bir parçası olarak kabul edilen, gençlik ve sağlık unsurlarını son derece ekonomik ve pratik biçimde bir araya getiren spor ve beden eğitimi aktiviteleri sunduğu sosyal, siyasal ve ekonomik faydaların yanı sıra 'bedeni (vücudu)' de görünür kılmaktadır. Böylece, cumhuriyetin en önemli kazanımı olarak nitelendirilebilecek kadın-erkek eşitliği ve laiklik noktalarına önemli bir vurgu yapılmaktadır. Doğramacı'ya (2010) göre siyasi erkin "batılılaşma, yeni değer ve normları"nı görünür kıldıklarını inandıkları aktivitelerden birini spor oluşturmaktadır. Çünkü batı modeline dayanan parlamenter demokrasi kurulmasını, bireylerin yeni imajı eşlik etmelidir: Cumhuriyet Türk insanı genç, aktif ve bedeninin bilincinde olmalıdır. Dolayısıyla da modernleşmenin ürünü olan spora, modern insanın yaşamında yer alan bir öğe, spor mimarisi yapı ve mekanlarına da modern kenti tamamlayan olmazsa olmaz unsurlardan biri olarak, cumhuriyetin bütüncül dönüşüm çalışmalarında en başından itibaren ayrı bir önem verilmiştir.

Bunun örneklerinden birini Ankara'nın ilk imar planlarında (1924) görmek mümkündür. Dr. Carl Christoph Lörcher tarafından çizilen planlarda Ankara istasyonunun kuzeydoğusunda bulunan bölgede şehir parkı ve sergi bahçesiyle birlikte spor alanları oldukça geniş olarak yer almıştır. 19 Nisan 1927 tarihli Erkan-ı Harbiye Reisliği'nin Başvekalet-i Celiliyye'ye ilettiği resmi yazı da dikkat çekicidir. Yazıda Ankara'nın Türkiye'nin spor ve beden eğitimi merkezi olması gerektiğinden ve yapılmakta olan sahanın tek başına ${ }^{5}$ bunu sağlayamayacağından bahsedilmektedir. Yazı ile Eğitim Bakanlığı, Milli Savunma Bakanlığı ve Ankara Belediyesi'nin ortak program hazırlayıp, bütçelerin birleştirilmesiyle Ankara için spor ve beden eğitimi okulu ve stadyumunu kapsayan bir spor merkezi yapılması gündeme alınmıştır (Korkmaz, 2007). Her yönüyle örnek şehir olarak kurgulanan Ankara'nın spor ve beden eğitimi merkezi için teori ve uygulama alanlarına duyulan ihtiyaç belirtilmiştir.

Türkiye İdman Cemiyetleri İttifakı'nın (TİCI) 3 Eylül 1927 yılındaki genel kongresine sunduğu raporunda Genel Kurmay Başkanlığı, sporun yaygınlaştırılması için yurt çapında spor sahası, kapalı bir soyunma-giyinme yeri, kapalı bir cimnastikhane ve tribünü olan stadlar yapılmasını teklif etmiştir. Bunun üzerine İçişleri Bakanlığı saha meselesini kesin şekilde halletmek için her şehirde bir spor stadıyla bir cimnastikhane yapılmasını içeren bir kanun hazırlandığını bildirmiştir (Özmaden, 1999). Aynı yıl içerisinde Ankara'nın mevcut imar

\footnotetext{
${ }^{4} \mathrm{Bu}$ hedefle Ankara'da, cumhuriyetle birlikte ulusal-toplumsal devrimlere rehberlik edecek kurumsallaşma ve yeniden yapılanma dönemine girilmiştir (Altaban, 1997). Diğer bir ifadeyle Türkiye için bir sıfır noktası, boş bir levha aranacaksa, burası Ankara'dan başka bir yer olmayacaktır (Kılınç, 2009).

${ }^{5}$ Maarif Vekalet-i Celilesi, 1927 bütçesinden Cebeci'de bir beden eğitimi okulu yapılması için 70.000 lira; Müdafaa-i Milliye Vekalet-i Celilesi de Ankara'da beden eğitimi okulu ve salonu inşası için 40.000 lira ayırmıştı. Ankara Şehremaneti (Belediyesi) tarafından ise Ankara'da stadyum yapılması için 1926 bütçesinden 5.000, 1927 bütçesinden ise 700.000 lira ayrılmıştı (Korkmaz, 2007).
} 
planının ihtiyacı karşılamaması üzerine bir yarışma açılmış, eleme sonucunda Prof. Dr. M. Jansen'in projesi seçilmiştir. Projenin onaylanma sürecinde (09.03.1929) Jansen'in sunduğu imar planına ait raporda Şehremaneti (Belediye) tarafından önerilen alanın, hem araçla hem de yaya gidenler için ulaşımının kolay ve rahat olması bakımından stadyum ve hipodrom yapımı için uygun olduğunu belirtmiştir (Korkmaz, 2007). TİCI'nin 1933 yılındaki 6. kongresinde Hükümet, 'Ankara Şehir Stadı'nın imar planına dahil edildiğini açıklamıştır. Cumhuriyet Halk Fırkası (CHF) Umumî Kâtibi Recep Bey kongrede stat ve saha ihtiyacını belirterek Ankara'dan başlanarak sıralı ve planlı bir çalışmayla bu gereksinimin karşılanacağı ifade etmiştir (Özmaden,1999).

Spor kompleksi alanı, sınırları ve bu komplesin içinde yer alan işlevler, Jansen tarafından hazırlanan imar planı ile belirlenmiştir. Jansen'in planı doğrultusunda Ankara'da yarış yeri ve stadyumdan oluşan spor merkezinin yapılması için uluslar arası bir yarışma düzenlenmesine karar verilmiş, bu amaçla tasarımda uzman kişiler resmi ve özel temaslar yoluyla (Korkmaz, 2007) belirtilen şartlara ${ }^{6}$ göre tekliflerini vermek üzere davet edilmiştir (Hakimiyet-i Milliye Gazetesi, 7 Mayıs 1933). Sonrasında belirlenen jüri üyeleri ${ }^{7}$ tarafından gelen projeler incelenerek seçim çalışmalarına ${ }^{8}$ başlanmış, mimar Vietti-Violi'nin sunduğu proje, Ankara'nın ihtiyacına daha uygun bulunarak seçilmiştir.

\section{Yapım aşaması}

Bu dönem için stadyumdan kastedilen, tek bir yapı değildir. Stadyum, içinde farklı sporlara ait ayrı ayrı fakat birbirleriyle ilişkili açık ve kapalı alanların, aynı zamanda bir tören ve merasim alanının ve spor okulunun da bulunduğu bir kompleks olarak ele alınmaktadır (Korkmaz, 2007). "Yapılacak stad dünyanın en asri tesisatı haiz ve adeta bir spor mahallesi olacaktır. Futbol sahasından etrafındaki atletizm, bisiklet pistlerinden maada; açık, kapalı kortları ve pistleri ${ }^{9}$ ihtiva edecektir" (Türkspor Dergisi, 15 Temmuz 1933). Her ne kadar stadyumun mimarı bir İtalyan olsa da yapının tasarımında ve inşasında pekçok Alman spor bilimci ve mimarının da önemli katkıları olmuştur. Riedel (1942) spor bilimcilerin katkısını, Türk hükümetinin Alman uzmanların (Prof. Dr. Altrock, Dr. C. Diem, Prof. March) fikirlerini inşaat başlamadan önce aldığını ayrıca inşaat başladıktan sonra da Dainas ve kendisinin spor tekniği konularında tavsiye vermeleri için sıklıkla çağrıldığını belirterek aktarmaktadır.

\footnotetext{
6 "İstasiyonla Büyük Millet Meclisi arasında yaptırılacak olan stadyom ve at yarışı yerinin bu sene inşasına başlanacaktır. Bunun için bir milyon lira temin edilmiştir, İnşaat kredi ile değil, peşin para ile yaptırılacaktır. Ankara vali ve belediye reisi Nevzat B., stadyom ve yarış yerini yaptırmak istiyen gruplara bu hususu tebliğ etmiş ve planlarında hayvanların koşması ve stadyomun maksadı temin edecek şekilde kullanılması şartlarını ihtiva edecek bir şekilde yalnız bir milyon liralık kısmının yaptıllacağını bildirmiştir” (Hakimiyet-i Milliye, 7 Mayis 1933).

${ }^{7}$ Yarışma jüri üyeleri; Cumhuriyet Halk Fırkası Umumi Katibi Kütahya Mebusu Recep Bey, Erzincan Mebusu Saffet Bey, Erzurum Mebusu Aziz Bey, Suvari Müfettişi Mürsel Paşa, Ziraat Vekilliği Müsteşarı Atıf Bey, Yarış ve Islah Encümeni Azasından Atıf Bey ve İmar Müdür Vekili İrfan Bey, Nafia Vekilliği Yollar Umum Müdürü Fehmi Bey ve Maarif Vekilliğinden Muallim Mektebi Müdürü Nizamettin Bey (Korkmaz, 2007).

8 "Yarış yeri ve stadyom projesini seçmeye memur hakem heyeti C.H.F. Umumi katibi Recep Beyin reisliği altında iki gece üst üste Halkevinde toplanarak projeleri tetkike başlamıştır. Bir Macar ve bir de İtalyan mütehassısları tarafından yapılmış olan iki proje mevcuttur. Heyet, bu iki plan üzerinde grupların mühendisleri tarafından verilen mufassal iyzahatı dinlemiştir. Heyet bu projelerden biri hakkında kararını bu günlerde verecektir. Birinciye üç bin, ikinciye binbeş yüz lira mükafat verilecektir" (Hakimiyet-i Milliye Gazetesi, 14 Haziran 1933).

9 "Bu hususta stadın mimarı Mösyö Viyotti Viyoli, demiştir ki: “... Bu eser bir defa ikmal edildikten sonra Türkiye hükümet merkezi, dünyanın diğer hiçbir büyük şehir veya merkezinde eşi bulunmıyan en asri, en mükemmel ve bir tek tesisat içinde bütün spor şubelerine ait kaffei tesisatı; at sporları, insan sporları bahusus her şekilde hafif atletizm sporlarını, futbol, bisiklet, tenis, mestur ve geyri mestur yüzme havuzlarını ilah.toplayan emsalsiz spor tesisatına malik olacaktır..” (Türkspor, 15 Temmuz 1933).
} 
Jansen (1937) ise Ankara planına dair raporunda, Dr. Carl Diem ile ortak bir proje hazırlayarak Ankara'da güneşin açısı sebebiyle spor saha ve tesisatının kuzey-güney doğrultulu yerleştirilmesiyle sporculara iyi spor yapma imkanının sağlanacağını vurgulamıştır.

\section{Açılışı}

Ankara imar planına uygun olarak inşa edilen Stadyum, üç gün devam edecek olan bir futbol turnuvası ile 15 Aralık 1936 tarihinde açılmıştır. Açılış günü yapılan Galatasaray-Ankaragücü maçının ilk vuruşunu Başbakan İsmet İnönü yapmıștır (Türkspor Kurumu Dergisi, 21 Aralık 1936; İspor Postas1, 21 Aralık 1936). İsmet İnönü'nün yanı sıra çok sayıda CHP milletvekili ile binlerce vatandaş açılışa katılmıştır (Top Dergisi, 21 Aralık 1936). Açılış kapsamında bir turnuva düzenlenmiş, bu kapsamda futbolu bırakmış isimler, bir gösteri maçı yapmıştır. “.... Yıllarca bu iş için uğraşmış olanların ilk modern Türk stadından bu suretle hisselerini almağa imkan verilmiş olması, bunları tertip edenlerin hususi bir itinası eser sayılmalıdır" (Türkspor Kurumu Dergisi, 21 Aralık 1936).

\section{Erken Cumhuriyet dönemi}

Stadyum, Cumhuriyet'in gerçekleştirmek istediği modernleşme projesinin mekansal karşıllı̆ 1 olarak görülebilecek bir anlayışla kurgulanmıştır. Stadyum aynı zamanda özellikle kapalı tribün tasarımı ile yapıldığı dönemin mimari özellikleri yansıtması açısından önemlidir. Kapalı tribün Cumhuriyet'in gerçekleştirmeyi arzuladığ $\breve{1}$ modernleşmenin biçimsel karşılığ1 olarak kabul edilen ve kullanılan modern mimarlık anlayışına göre tasarlanmıştır. Kübik kütle anlayışıyla biçimlenen kapalı tribünde kullanılan geniş cam yüzeyler, girişlerin üzerindeki betonarme saçaklar ve yalın cephe anlayışı, 'balkon platform' şeklinde tribünlerden önde tasarlanan localar dönemin mimari özelliklerini yansıtmaktadır (Korkmaz, 2007).

Stadyum erken cumhuriyet dönemi mimari örneklerinden biri olması yönü ile spor tarihi için olduğu kadar mimarlık tarihi açısından da ayrı bir yere sahiptir. Türk Spor Kurumu Dergisi'nin 21 Aralık 1936 sayısında Ankara stadyumunun açılışına dair bir haberdeki şu paragraf bu önemi teyit eder niteliktedir. "Bir atlet vücudu nasıl süse muhtaç değilse bütün lüzumsuz ziynetlerden; zinde bir insanın elinde baston nasıl fazla görünürse, mesned vazifesini gören direklerden tecrid edilmiş cüretli bir mimarinin, spor tekniğini de yardımına alarak meydana getirmiş olduğu kusursuz eser: Ankara stadyomu.."

Stadyumun açılışının yansımaları stadyuma ve stadyumun işlevlerine yönelik bakışı ve genç cumhuriyetin ulaşmak istediği hedefleri de ortaya koymaktadır. "Türkin ürki ve fikri kuvvetini, her şeyde olduğu gibi daima yüksek tutacak olan böyle idman ve savaş sahalarını her yere götürmek, Cumhuriyetin hedef ittihaz ettiği şaşmaz umdelerinden biridir (İçişleri Bakanı ve CHP Genel Sekreteri B.Şükrü Kaya)"; “Genç Türkiye, 'zaman'ı spor alanında bir daha yendi. Disiplin ve nizam, her sahada olduğu gibi spor sahasında da muvaffakiyetin birinci amili oluyor. ... Ankara, yeni stadyomu ve yeni takımlarile, hükümet merkezi, her türlü kültür merkezi olduğu gibi, artık, spor merkezidir, kültür fizik merkezidir de (Behçet Kemal Çağlar)" (Türkspor Kurumu Dergisi, 21 Aralık 1936). Spor alanları aynı zamanda gelecek nesillerin cumhuriyet idealleri doğrultusunda yetiştirileceği okullar olarak kabul edilmektedir. Stad açılışında konuşan İsmet İnönü’nün “... Türkiyeyi idare edenler, stadyumu en kıymetli mekteb gibi her yerde kurmaya çalışacaklardır. Türkiyenin istikbalini idare edecek olan genç nesil, açık havada açık meydanlarda yetişecektir" sözleri stadyumun okul olma işlevini ortaya koymaktadır (Türkspor Kurumu Dergisi, 21 Aralık 1936). "Bizim gençliklerimiz için stadyomlar, mektepler kadar mühimdirler. Biz zeka terbiyesinin fiil ve hareket hassalariyle tamamlanmasına, bildiğimiz ve düşündüğümüz kadar yapmağa muhtacız. Ankara stadyomunu 
vücuda getirenleri tebrik ederiz (Atay, 1936) ". Yeni Türkiye'nin inşasında ihtiyaç duyulan çalışan ve mücadeleci 'gürbüz ve genç' neslin yetiştirilmesi yolunda stadyum önemli bir altyap1 eksikliğini gidermiştir. Bir anlamda stadyumun varlığının, modern başkent projesi ve yaratılmaya çalışılan genç cumhuriyet için itici güç olacağı düşünülmüştür (Korkmaz, 2007).

Stadyum da model şehir olarak tasarlanan Ankara'nın bir parçası olarak ele alınmıştır. Bu anlamda şehir planlamalarında yer verilen spor ve rekreasyon alanları, modernleşmenin parçası olarak düşünüldüğü gibi, ülke gelişmişliğinin ve ilerlemesinin de göstergelerinden biri olarak kabul edilmiştir. Stadyum, aynı zamanda hem gençlerin spor yaptığ 1 hem de sportif etkinlik ve törenlerde halkın bir araya geldiği kamusal bir alan olmuştur. Ankara'nın sosyal ve sportif yaşamına canlılık getiren etkinlikler ve bayram, yıldönümü, kutlama gibi organizasyonlar aracılığıyla ulus olma bilincinde, Cumhuriyet değerlerini ve yeni yaşam alışkanlıklarını benimsemiş nesiller yetiştirmek ${ }^{10}$ yoluyla toplumun dönüştürülmesi hedeflenmiştir.

$\mathrm{Bu}$ anlamda devrimlerin topluma benimsetilmesi, milli sembollerin yüceltilmesi ve çağdaşlaşma yanlısı temaların vurgulanması amacıyla bayramların düzenlendiği yer olarak stadyumlar ve spor alanları, tam anlamıyla batılılaşmış, kadın ve erkeklerin bir arada bulunduğu toplum düşüncesinin ve yeni modern yaşantının mekansal karşılıkları olarak iktidar tarafından ele alınmıştır (Doğramac1, 2010; Bozdoğan, 2015; Korkmaz, 2007). Dönem yayınlarda da sıklıkla kadın bedeni spor yaparken ve spor yapanları izlerken gösterilmiştir (Ulus Gazetesi, 19 Mayıs 1938; İspor Postas1, 1934). Ayrıca stadyumun tasarımında yer alan hitap balkonları, liderlerin halka seslenmesini sağlamakla birlikte halkın da iktidarı görme arzusunu karşılamış, iktidarla buluşmasını ${ }^{11}$ sağlamıştır (Yeşilkaya,1999). Stadyum, Atatürk'ün katıldığı son bayrama da 1938 yılında ev sahipliği yapmıştır. İlerleyen hastalığına rağmen törene katılan Atatürk, halk tarafından coşkuyla selamlanmış, gösterileri büyük bir ilgiyle takip etmiştir. 19 Mayıs Gençlik ve Spor Bayramı töreninde öğrencilerin spor gösterileri, gençlik marşının hepbir ağızdan okunmuş, akrobasi uçaklarının gösterileri ${ }^{12}$ yapılmıştır. Halka açık kamusal alanlarda kurucu kadroların halkla ve aynı zamanda halkın birbiriyle temas edeceği etkinlikler ve mesajlarla yeni yaşam biçiminin/tarzının yaygınlaştırılması sağlanmaya çalışılmıştır.

Türkiye'de gerçekleştirilen ilk stadyum yapısı olması açısından büyük önem taşıyan yapı dönem koşullarında önemli bir prestij ${ }^{13}$ kaynağı olmuştur. Stadyumun yarışma aşamasından

\footnotetext{
10 İçişleri Bakanı Şükrü Kaya'nın 19 Mayıs Bayramına dair yazdığı resmi yazıda yurttaşların dönüştürülmesi hedefini görmek mümkündür; “... 19 Mayıs SPOR VE GENÇLİK bayramı adını vereceğimiz bu bayram, ayrıca bütün millete güzel insan, hareketli insan, canlı insan, uyanık insan, dürüst insan, mert insan idealini aşılamak, hava, 1şık, su, dağ sevgisini sindirmek, temizlik, sağlamlık ve güzellik aşkını yerleştirmek ve artırmak için bir vesile sayılacaktır. C.H. Partisi bunu böyle anlamaktadır.” (BCA. 19 Mayıs Gençlik ve Spor Bayramı'nın Kutlanmas1. 490.1.0.0/3.15.18/11.05.1937).

11 “Cumhuriyet'in onuncu yıldönümü bayramında, Gazi Mustafa Kemal'in Türk milletine hitabesi, bir devir başlangıcının, bir yeni sabahın ilk işareti gibi olmuştu. ... Şimdi betondan ve kara Ankara taşından stadyum'un sade ve gürbüz endamının yükseldiği yerde, o vakit, çam tahtalarından, derme çatma birtakım tribünler vardı. Şimdi, yeşil çimenle örtülü saha, o vakit, boş, çıplak ve yalçın bir çöl parçası idi ve üstünde civar köylerden, kasabalardan gelmiş bir alaca halk yığını kaynaşıyordu” (Karaosmanoğlu, 2011).

${ }^{12}$ Uçaklar, tören alanına '19 Mayıs güven, sevinç, hareket günüdür', 'Vücudunu ve kafanı işlet', 'Vücudu güzel tutmamak ayıp işlemektir', 'Dedikodu yapma spor yap', 'Güzelliğin temeli sağlıktır' vb halka spor yapmayı telkin eden dövizleri bırakmıştı (CHP Genel Sek. 19 Mayıs Spor ve Gençlik Bayramı Kutlama Talimatı, 1938).

13 “Ankara Stada kavuşuyor.. Ankara ile beraber bütün Türkiye ve bütün Türk gençliği modern tesisatı ihtiva eden, bütün ihtiyaçlara toptan cevap veren büyük bir stadyuma sahip olmak üzeredir. Artık Türkiye şampiyonalarının mektep avlularında oynanmasından kurtulmuş oluyoruz. Artık her hangi beynelmilel bir temas için ecnebilere karşı göğsümüzü gere gere "işte Stadımız, buyurun burada karşılaşalım” diyebilecek bir vaziyete
} 
tamamlandığı zamana kadarki tüm süreç ve gelişmeler gazeteler yoluyla kamuoyuna duyurulmuştur (Korkmaz, 2007). Yayın yoluyla gerek stadyumlara duyulan ihtiyaç gerekse Ankara stadyumunun spor mimarisi ile ilgili teknik bilgiler ve incelemeler de halka aktarılmıştır ${ }^{14}$. Geleceğin örnek kenti olması, modern dünyanın kabul görmüş estetiğini son sınırına kadar yansıtması düşüncesiyle ulus düşüncesinin örnek yaşama mekanı olarak kurgulanan (Işın, 2009) Ankara'da stadyumun sporun ilerlemesi anlamında da gerekliliğine değinilmiştir. "Ankara Stadyomu, Avrupadaki benzerlerinin inşasında edinilmiş olan tecrübelerden istifade olunarak salahiyetli mühendislerce yapılan projelere göre Türkiyede ilk defa kurulmuş, eksiksiz bir tesistir. ... Ankara stadyomu, Balkanların ve Avrupanın birçok büyük şehirleri için gıpta olunacak derecede azametli, zarif bu devrin bir mimari eseridir ${ }^{15}$. Bundan böyle diğer şehirlerimizde birer birer yükselecek olan stadlar, muhakkak ki, Ankara stadyomunu kendilerine örnek tutacaklar ve sporumuz dahi bu güzel rekabet sayesinde daha teknik esaslara dayanarak ilerliyecektir. Zira stadyomlar bir dekor değildir ve çemenli sahalar, usulüne göre tanzim olunmuş pistler, sporun telakkisi ve yeni rekorların teessüsü için çok lüzumlu vasitalardır" (Türkspor Kurumu Dergisi, 14 Aralık 1936) ${ }^{16}$. Bu anlamda Erken Cumhuriyet Dönemi'nden itibaren pek çok işlevi yerine getiren 19 Mayıs Stadyumu, uzun yıllar gençlik ve spor bayramlarına, çeşitli kutlama ve anmalara olduğu gibi sportif pek çok organizasyon düzenlenmiştir.

\section{Erken Cumhuriyet sonrası ve günümüzde}

Uzun yıllar lig maçları düzenlenen stadyum, Ankara takımları arasında düzenlenen çeşitli turnuvalar çerçevesinde futbol karşılaşmalarının yanı sıra güreş, voleybol gibi farklı spor branşlarında maçlar, şampiyonalar vs de ev sahipliği yapmıştır. Toplam 28 milli maç yapılan stadyumda, en son milli maç 25 yıl önce gerçeklemişti, son senelerde saha zeminin kötü durumundan dolayı stad, futbol maçları için elverişsiz hale gelmişti. Birkaç seneden beri

geçiyoruz” (Mitat, 1934). “... İlk üç günde arka arkaya yapılan müsabakalarda tribünler hınca hınç dolmuş ve 35 40 bin Ankaralı yeni stadın ilk seyircileri olmuşlardır. ... Ankara stadyomu, Ankaranın genç sporcusu ile yaşıd telakki edilebilir. ... Avrupanın ileri spor teşekkülerini temsil eden kulüblerini artık, açık alınla karşılayabiliriz. Çünkü onlara gösterecek ve onları imrendirebilecek bir spor sahamız vardır. ... 19 Mayıs Stadyomunun memleket sporu bakımından doldurduğu yeri ${ }^{13}$ anlatabilmek için bir buçuk senelik temas ve seyirci sayısını zikretmek kafi gelecektir. ... Dünya sporcularının hükümet merkezimizin modern stadına aktıklarını göreceğimiz gün uzak değildir" (Gençosman, 1938).

14 “Ankara Stadyom ve Hipodromunun yapısı, proje ve planına göre ilerlemektedir. Yalnız Ankaranın değil Türkiyenin en güzel spor yeri olacak olan Stadyom ve Hipodromun inşa vaziyeti hakkında Ankara vilayeti nafia müdürü B.Muammer'in, bakanlık makamı için hazırladığı raporda bazı kısımları alıyoruz ... Ankara stadyomu ve hipodromu, istasyonu şehre bağlayan büyük bir asfalt yolun üzerinde, yeni gar ve Gençlik parkı ile, baş şehrimize gelenlerin gözü önünde cumhuriyetin büyük eserleri arasında yer alacak bir varlıktır. Şen, gürbüz, sıhhatli ve güler yüzlü bir geçlik yetiştirmek davasında olan cumhuriyetimizin memlekete bir örnek olarak verdiği bu eşsiz alanın tarihinin, birçok milletlerarası rekor ve başarılarla bezenmesini temenni ederiz" (Ulus, 23 Mart 1936).

${ }^{15}$ Vurgu bana ait.

16 "Yeni Ankara Türk inşacılığının en güzel misalerile doludur. Ankaranın her büyük binası, bu binalarının yeni yeni motifleri, muasır mimarinin bunlarda tatbik ettiği türlü şekiller diğer şehirlerimiz için geniş bir ilham kaynağı olmaktadır. Ankara Stadyomu ise, bizde bu çeşit mimarinin ilk, fakat en mütekamil eserlerinden biri olmak bakımından, bütün diğer şehirlerimizin yaptıracakları stadlar için tek örnek sayılarak her vakit tetkik olunacak ve onun ebadı değilse bile tribünlerinin biçimleri, tribünleri altına ve arkasına, türlü ihtiyaçları tatmin etmek üzere, maharetle yerleştirilmiş olan salonları, çimenli çayırlarının, koşu pistlerinin, atma ve atlama havuzlarının ve geri kalan bütün kısımlarının yapılış tarzı kopye edilecektir” (Türkspor Kurumu Dergisi, 13 Temmuz 1936). 
dillendirilen stadın çürük raporunun açıklanmasının ardından, birkaç yıl önce mevcut yerine yeniden yapılmak üzere yıkılmasına karar verilmiştir ${ }^{17}$.

19 Mayıs Stadyumu için alınan ve uygulamaya konulan yıkım kararı, erken cumhuriyet dönemine ait mimarlık tarihi ve spor tarihi mirasının varlığının ortadan kalkması anlamına gelmektedir. Ankara'nın büyük kapasiteli, çağdaş bir futbol stadyumuna olan ihtiyacı elbette ki görmezden gelinemez. Ancak yap1 çevresinde faaliyet gösteren amatör spor kulüplerinin çalışma yapacakları alan ihtiyacı en az stad kadar önemli bir gereksinimi oluşturmaktadır. Ayrıca Beşiktaş İnönü Stadı'nın yıkılmasıyla ülkesi İtalya'da benzer tarihlerde tasarladığı spor yapıları koruma altına alınmış olan Paolo Vietti-Violi'nin, ülkemizdeki tek stadyum yapıs1 olan ve döneminin mimari özelliklerini yansitan (http://www.mimarlarodasiankara.org/?Did=9616\&utm_source=dlvr.it\&utm_ medium=facebook) stadyumun, yeni plan ve projesi ile ilgili 50 bin kişi kapasiteli olacağ ve futbol dişında bazı sosyal etkinliklerde kullanılacağı dışında kamuoyu ile paylaşılan bir bilgi bulunmamaktadır. Mimarlar Odası Ankara Şubesi'nin yürütmenin durdurulması için konuyu yargıya taşımıştır. Alanın tescilli kültür varlığı olarak gelecek kuşaklara aktarılmasına için Ankara 2 Numaralı Kültür Varlıklarını Koruma Kurulu'nun stadyum hakkındaki 'korunması gereken kültür varlığı' şerhini kaldıran kararını yargıya taşımıştır (http://www.mimarlarodasiankara.org/index.php?Did=9062) ancak tescil davasının devam etmesine rağmen stadın yıkım işlemine başlanmıştır ${ }^{18}$.

Elbette ki zaman içerisinde yaşanan yıpranma ve işlevini kaybetme durumlarında kentsel dönüşüm kaçınılmaz bir gerekliliktir. Ancak toplum (ve dolayısıyla kent) hızla değişirken, geleneksel 'anımsama ortamlarını' ortadan kaldırmakta; ama aynı başarıyı yeni 'anımsama mekanlarını' yaratmakta gösterememekte (Tanyeli, 2002), spor mekanları ve yapıları da bundan payını almaktadır. Bugün 19 Mayıs Stadyumu örneğini bu çerçevede değerlendirmek mümkündür. $\mathrm{Bu}$ noktada akla gelen soru "yeni mekanlar yaratılamadığı günümüz koşullarında mevcut alanları yaşatmak için yapılabileceklerin neler olduğu"dur. Bu da bizi sürdürülebilirlik ve miras konusuna tekrar götürmektedir.

\section{Sürdürülebilir spor kültürrü için spor mirası aktarımı}

Sürdürülebilirlik üç alt sistemin, kalkınma isteyen toplum, kültürel çevre ve doğal çevre, her birinin kendisini geliştirip yeniden üreterek toplu olarak gelişmesini sürdürmesi anlamına gelmektedir (Tekeli, 2003). Spora ilişkin her türlü değeri, ürünü ve davranışı belirten (Kaplan, Akkaya, 2014) spor kültürünün geliştirilmesi ve sürdürülebilirliği, haftada bir ya da iki saatlik beden eğitimi derslerinden daha fazla ve daha farklı uygulamaları gerektirmektedir (Kasap, Spor kültürünün oluşmasında beden eğitimi öğretmeninin önemi ve katkıları. http://www.sporbilim.com/dosyalar/3_B_E_S_O_O_E_S_K_S_Paneller.pdf). Bu anlamda sporun kendi içerisindeki başarıları ana ve spor kültürünün de içerisinde sıkı sıkıya yer aldığı bir anlatı yaratan 'Spor mirası' (Ramshaw ve Gammon, 2005) öne çıkmaktadır. Spor mirasının yüklendiği misyonlar, sadece kişiye geçmişi hatırlatmasından ibaret değildir. Bireylerin sosyalleşmesini sağlamak, kültürün nesiller arasında taşınmasında köprü görevi görmek gibi çok geniş yelpazedeki birçok işlevle toplum yapısını çok derinden etkilemektedir. Sportif birikimine dair bilinçlenme platformu işlevini yerine getiren spor

\footnotetext{
${ }^{17}$ http://t24.com.tr/haber/19-mayis-stadinin-yikimi-basladi,670735; https://www.ahaber.com.tr/gundem/2018/06/02/ankarada-19-mayis-stadina-dev-mitingle-veda; http://www.cumhuriyet.com.tr/haber/spor/704293/Ankara_ya_yeni_stadyum_yapiliyor.html ${ }^{18}$ https://www.dha.com.tr/foto-galeri/tarihi-stadin-yikim-calismalari-basladi/haber-1590112/p-5; http://www.milliyet.com.tr/efsane-stadin-yikimi-basladi--mke-ankaragucu-2707745-skorerhaber/ http://www.hurriyet.com.tr/efsane-19-mayis-stadinin-yikimi-basladi-40899181
} 
mirası alanlarını korumak spor kültürüne dair farkındalık oluşturulmasına doğrudan bir katkı yapmaktadır.

Kültürün toplumdan topluma farkl1lık göstermesine paralel olarak spor kültürü ve spor mirasları da toplumdan topluma çeşitlilik arz etmektedir. Örneğin Kurtdereli Mehmet Pehlivan'ın Avrupa'da yaptığg güreşler sorulduğunda “Güreşirken, bütün Türk milletini arkamda hisseder ve onun şerefini korumak için her şeyi yapardım. Ve sanki bütün Türk milletinin kuvvetinin arkamdan dayandığını hissederdim" sözleri üzerine Atatürk'ün Kurtdereli'ye yazdığı mektubunda "bu değerli sözünü Türk sporcularına bir meslek düsturu olarak kaydediyorum" sözleri ülkemiz spor tarihi ve halkımız açısından değerli iken başka bir toplum için anlam ifade etmeyebilir. Önemli olan kendi spor kültürümüze ve tarihimize dair olan mirası korumak ve yeni nesillere aktarabilmektir. Çünkü her kuşak kendi geçmişini yeniden keşfetmek durumundadır. Dolayısıyla devamlılık (sürdürülebilirlik) hiç olmadığı kadar değer kazanmıştır (Shaukland, 1996).

Spor kültürümüz açısından spor mirasının sürdürülebilirliği için spor tarihimizde yer edinmiş gerek eğitim gerek organizasyonel ve yönetsel boyutlarıyla iz bırakan isimlerin mirasının sergilenmesi ve sunulması büyük önem taşımaktadır. Bu anlamda spor tarihimizde yeri olan kişiler adına (Selim Sırrı Tarcan, Burhan Felek, Naili Moran veya Naim Süleymanoğlu Araştırma Enstitüsü gibi) açılacak araştırma enstitüleri, genç araştırmacıların çalışacakları ve yeni projeler üretecekleri platform işlevini yerine getirecektir. Bunun yanı sıra 'Selim Sırrı Tarcan olimpik araştırma ödülü', 'Ali Faik Üstünidman sporda teknoloji kullanımı ödülü’ gibi çeşitli isimler altında oluşturulacak ödüller, hem ödüle ismi verilen kişiyi yaşatacağı gibi o kişinin adını taşıyan bir ödülü edinmek isteyen araştırmacıları da teşvik edecektir. Turnuvalara veya spor salonlarına isimleri verilen geçmişin spor insanlarını, bu turnuvalarda sunulacak veya salonlarda konumlandirilacak alanlarda yansitılan (belirli periyodlarla güncellenen) interaktif video ve benzeri uygulamalarla tanitılması, yeni nesillerin bu isimleri benimsemelerini sağlayacaktır. Ülkemiz spor tarihini anlatan bir spor müzesinin bulunmayış1 da çok büyük bir eksikliği oluşturmaktadır. Bu konuda yakın geçmişte İstanbul Büyükşehir Belediyesi'nin Spor Müzesi Çalıştayı ${ }^{19}$ düzenleyerek müzenin açılması konusunda bir girişimi olduysa da proje sonuçlandırılamamıştır. Ülkenin spor alanına ait envanter kaydının çıkarılması ve konunun yasal dayanaklarla desteklenmesi daha hızlı bir şekilde müze veya araştırma merkezi/leri kurulması için hareket edilmesini olanaklı kılacaktır. Kısacası sporda sürdürülebilirliği sağlamak için gerekli kanalların ve yolların miras aktarımının sağlamak amacıyla açık olması, yani bir diğer ifadeyle mirasın korunması ve erişilebilirliğinin sağlanması gerekmektedir.

\section{TARTIŞMA VE SONUÇ}

Osmanlı'dan farklı bir 'biz' (Bora, 2012) olma anlayışla hem geçmişin 'sağlıssız' yapılanmasından kurtulmak, hem de fikren ve fiziken 'sağlıklı' bireyler üretmek hedefiyle (Kılınç, 2009; Akın, 2014; Arpacı, 2015) genç cumhuriyette 'gençlik', 'sağlık', 'asrilik ${ }^{20}$, laiklik, kadın-erkek eşitliği gibi unsurlar yaşamın her alanında başlıca referanslar yapılmıştır. 'Yeni Türkiye'nin 'sağlıklı' bireylerinin üretecekleri kollektif modern yaşamın 'sağlıklı' bir mekânsal organizasyonla yani modern yaşamın birebir mimari karşılıklarının üretilmesiyle (Kılınç, 2009) mümkün olabileceği anlayışının yansıması olarak hızla kadın ve erkeğin bir

\footnotetext{
${ }^{19}$ https://www.ibb.istanbul/News/Detail/27538. Erişim tarihi: 5 Aralık 2018

${ }^{20}$ Yüzyılın uygarlık düzeyini yakalama ve hatta aşma isteği, Cumhuriyet'in ilk 10-15 yılında 'asri' sözcüğüyle somutlaşmıştır (Çiçekoğlu,1998). (Kavrama dair detaylı okuma için Çiçekoğlu F. Asri, Modern, Çağdaş. Üç Kuşak Cumhuriyet içinde. (Ed.Uğur Tanyeli). İstanbul: Tarih Vakfı Yayınları; 1998, s:146-153.).
} 
arada olacağı spor ve rekreasyon alanlarının yapımına girişilmiştir. Örnek bir kent inşa ederek modern ve çağdaş yaşam ortamı oluşturmak, bu yeni kentsel mekanda geliştirilecek yeni sosyal normlarla Anadolu'nun kentleşmesine öncülük etmek ve en önemlisi Cumhuriyet'in 'başarılarını' yeni başkentte sembolize etmek gayesiyle (Tekeli, 1984) 'asriliğin' ve 'ilerlemenin' göstergesi olarak Ankara'da inşa edilen 19 Mayıs Stadyumu modernleşme ideallerini temsil eden bir yapı olarak öne çıkmaktadır.

Yapımı ve açılışı dönem gazetelerinde dizi haber olarak verilen, inşa edildiği zamanın ekonomik, sosyal ve siyasi beklentilerini ve fikri atmosferini yansitan stadyum, cumhuriyetin kurucu kadrolarınca sporun nasıl ele alındığı ve önemsendiğini ortaya koyan bir yapıdır. Spor kültürünün oluşumunda ve gelişiminde spor mirası aktarımının önemi düşünülecek olunduğunda stadyumun varlığı ve anlamı daha net ortaya çıkmaktadır. Bu sebepten ülkemiz spor belleğinin taşıyıcısı niteliğindeki stadyum erken cumhuriyet döneminin, idealize ettiği 'gençlik' ve 'sağlık' niteliklerinin mekânsal karşılığını oluşturan kamusal alanlardan bir tanesi, mirasımızın önemli bir parçasıdır. Cumhuriyeti var eden Ankara'nın sembol yapılarından biri olan, birçok spor dalına hizmet eden 19 Mayıs Stadyumu bıraktığı sosyal, kültürel, sportif izler ve anılar ile pek çok insanın hafızasında ve toplumsal bellekte ayrı bir yer edinmiştir.

Stadyumun mirası yönü ele alınması gerektiği kadar tesis işletmeciliği yönü ile de değerlendirmek gerekmektedir. Tesis işletmeciliği anlamında bakıldığında stadyumun eskrim, tenis, güreş, atletizm gibi branşlardaki kullanım yoğunluğu göz önüne alındığında sadece futbol branşına yönelik yapılacak bir yatırımın tesis kullanımı anlamında daha düşük bir kapasite ile çalışacağı görülmektedir. Pek çok spor branşının gereksinimlerini hala karşılayabiliyor olması dolayısıyla stad, tesis anlamında işlevini yerine getirmektedir. Diğer branşların da yararlandığı yapının ortadan kalkması spora katılımın desteklenmesi, sporun ve spor kültürünün yayılması anlamında olumsuz bir tablo ortaya çıkarmaktadır. Bununla birlikte Ankara 19 Mayıs Stadyumu'nda olduğu gibi döneminin önde gelen mimar ve mühendisleri tarafindan tasarlanan, bugün hala çeşitli şampiyona ve organizasyonlara ev sahipliği yapan Berlin Olimpiyat Stadyumu'na bakıldığında, her iki stadyumun da 1936 yılında tamamlanarak kullanılma açıldığı göz önüne alındığında durum daha net okunabilmektedir. Berlin Olimpiyat stadyumu, spor merkezi olarak işlevini sürdüren tesisin aynı zamanda bir miras alanı olarak nasıl korunduğuna çarpıcı bir örneği oluşturmaktadır. Bu açıdan bakıldığında sürdürülebilir tesis işletmeciliği anlamında da spor kültürü anlamında da geleneğe bakış ve geleceğin şartları çerçevesinde yenilenme ve koruma noktalarındaki ülkemizdeki eksikliğin sorgulanması gerekmektedir.

Spor bilim dünyasında pek tartışılmıyor olsa da bugün yıkımı başlatılan stadyumun korunması amacıyla Mimarlar Odası Ankara Şubesi, Gençlik ve Spor Bakanlığı'na karşı dava açmış bulunmaktadır. Yapılacak yeni stadyuma dair ise kamuoyuyla paylaşılan detaylı bilgi bulunmamaktadır. Erken cumhuriyet döneminin simge mekânlarından yapının yıkımı ile olumsuz bir miras aktarımı, daha doğrusu mirasın ve dolayısıyla kültürün aktarılmaması söz konusudur. Bugün için belki stadyumu yaşatmak adına bir adım atmak için geç kalınmış olsa da en azından bu yıkım üzerinden spor miras ve kültürümüzün aktarımına dair değerlerimizi nasıl yaşatacağımız ve aktaracağımızla ilgili bir tartışma alanı açmak bundan sonrası için olumlu bir adım olacaktır.

\section{KAYNAKLAR}

Akın, Y. (2014). Gürbüz ve Yavuz Evlatlar: Erken Cumhuriyet'te Beden Terbiyesi ve Spor. İstanbul: İletişim Yayınlar1. 
Aksu, A. (2011). Spor sosyal ortamı olarak stadyumlar. Mimarlık Dergisi, 48(360), 44-49.

Altaban, Ö. (1997). Ulusal yönetimin ve toplumsallı̆̆ın kurgulandı̆̆ı bir başkent. Arredamento Dergisi. 3(90), 89-94.

Arpac1, M. (2015). Modernleșen Türkiye'de Beden ve Nüfus Politikaları: Hıfzısıhha, Terbiye, Öjeni. Yayınlanmamış Doktora Tezi. Mimar Sinan Üniversitesi. Sosyal Bilimler Enstitüsü.

Atay, F.R. (1936, 15 Aralık). Ankara Stadyumu. Ulus Gazetesi, s.1,5.

Başbakanlı Cumhuriyet Arşivleri. 19 Mayıs Gençlik ve Spor Bayramı'nın Kutlanması. 490.1.0.0/3.15.18/11.05.1937.

Bora, A. (2012). Bir milli vazife olarak spor ve kadınlar. Hacettepe Spor Bilimleri Dergisi, 23(4), 220- 226.

Bozdoğan, S. (2015). Modernizm ve Ulusun İş̧ası: Erken Cumhuriyet Türkiyesi’nde Mimari Kültür. İstanbul: Metis Yayınları.

Cumhuriyet Halk Partisi Sekreterliği. (1938). 19 Mayıs Spor ve Gençlik Bayramı Kutlama Talimatı. Ankara: Ulus Basımevi.

Çiçekoğlu, F. (1998). Asri, modern, çă̆daş. (Uğur Tanyeli Ed.) Üç Kuşak Cumhuriyet. s.146-153. İstanbul: Tarih Vakfi Yayınları.

Demirci, A. (2014). Literatür Taraması. (Yılmaz Arı, İlhan Kaya Eds.) Coğrafya Araştırma Yöntemleri. s.73108. Balıkesir: Coğrafyacılar Derneği Yayınları.

Doğramac1, B. (2010). Heading into modernity: sporting culture, architecture and photography in the early Turkish Republic. (N Katzer, S Budy, A Köhring, M Zeller, Eds.). In: Euphoria and Exhaustion: Modern Sport in Soviet Culture and Society. s.111-126. Frankfurt: Campus Verlag.

Eagleton, T. (2005). Kültür Yorumları. (Ö Çelik Çev.). İstanbul: Ayrıntı Yayınları.

Gençosman, K.Z. (1938, 24 Mayıs). Gürbüz gençliğin toplantı yeri: 19 Mayıs Stadyomu. Ulus Gazetesi, s.10.

Işın, E. (2009). Ankara Cumhuriyeti İnşa Eden Kent. (E Işın, Ed.). Ankara: Kara Kalpaklı Kent 1923-1938. s. 11-15. İstanbul: İstanbul Araştırmaları Enstitüsü.

Jansen, H. (1937). Ankara İmar Planı Raporu. İstanbul: Alaaddin Kıral Basımevi.

Kaplan, Y., Akkaya, C. (2014). Spor Kültürü ve Türkiye'de Spor. International Journal of Culture and Sport, Special Issue. 1(2), 114-119.

Karaosmanoğlu Y. (2011). Ankara. İstanbul: İletişim Yayınları.

Karasar, N. (2007). Bilimsel Araştırma Yöntemleri. Ankara: Nobel Yayınları.

Kasap H. Spor kültürünün oluşmasında beden eğitimi öğretmeninin önemi ve katkıları. http://www.sporbilim.com/dosyalar/3_B_E_S_O_O_E_S_K_S_Paneller.pdf Erișim tarihi: 7 Temmuz 2018.

Keser, İ.K. http://kisi.deu.edu.tr//istem.koymen/BAY\%20sunum\%202.pdf Erişim tarihi: 18 Aralık 2018.

Kılınç K. (2009). Öncü halk să̆lı̆̆ projelerinin kamusal mekanı olarak Sıhhiye. (GA Sargın, Der.). Ankara'nın Kamusal Yüzleri: Başkent Üzerine Mekan Politik Tezler içinde. s.119-156. İstanbul: İletişim Yayınları.

Koçak F, Tuncel F, Tuncel S. (2013). Sporda sürdürülebilirliğin boyutlarının belirlenmesi. Ankara Üniversitesi Spor Bilimleri Fakültesi Dergisi, 11(2), 113-129. 
Korkmaz Z. (2007). Ankara 19 Mayıs Stadyumu'nu (Ankara Milli Stadı'nı) okumak: Erken Cumhuriyet döneminde mekan, toplumsal yaşantı ve ideoloji ilişkisi. Yayınlanmamış Yüksek Lisans Tezi. Gazi Üniversitesi. Fen Bilimleri Enstitüsü.

Mitat T. (1934, 12 Mayıs). İstanbula stadtan evvel kapalı saha lazım. Türkspor Dergisi, 5(33-240), 3.

Özmaden, H. (1999). Cumhuriyet Dönemi İlk Spor Teşkilatı Türkiye İdman Cemiyetleri İttifakı (1922-1936)nın Yapılanma Sürecinde Beden Eğitimi ve Sporun Fonksiyonları, Fonksiyonlardaki Değişimler ve Toplumsal Hayata Etkileri. Yayınlanmamış Doktora Tezi. Marmara Üniversitesi. Sağlık Bilimleri Enstitüsü.

Ramshaw, G., Gammon, S. (2005). More than Nostalgia? Exploring the Heritage/Sport Tourism Nexus. Journal of Sport Tourism, 10(4), 229-241.

Ramshaw G. (2011). The Construction of sport heritage attractions. Journal of Tourism Consumption and Practice, 3(1), 1-25.

Riedel H. (1942). Leibesübungen und Körperliche Erziehung in der osmanischen und kamalistischen Türkei. Würzburg: Konrad Triltsch Verlag; 1942.

Shaukland G. (1996). Tarihi Değerleri Olan Kentlere Neden El Atmalıyız. Çev. Kamran Tuncay. Cogito Dergisi. Kent ve Kültürü dosyası. 8:17-36.

Tanyeli U. (2002). Önsöz. (Ali Cengizkan). Modernin Saati: 20.Yüzyılda Modernleşme ve Demokratikleşme Pratiğinde Mimarlar, Kamusal Mekan ve Konut Mimarlığı içinde. İstanbul: Mimarlar Derneği Yayınları.

Tekeli İ. (2003). Kültürel Mirasın Sürdürülebilirliği Üzerine Irdelemeler. https://www.academia.edu/30941548/K\%C3\%9CLT\%C3\%9CREL_M\%C4\%B0RASIN_S\%C3\%9CRD\%C3\%9 CR\%C3\%9CLEB\%C4\%B0L\%C4\%B0RL\%C4\%B0\%C4\%9E\%C4\%B0_KAVRAMI_\%C3\%9CZER\%C4\%B0 NE_\%C4\%B0RDELEMELER. Erişim tarihi: 14 Temmuz 2018.

Tekeli İ. (1984). Tarih İçinde Ankara. Ankara: ODTÜ Yayınları.

Tonta Y. (2014). Kültürel Mirasın Geleceği. Uluslararası Kültürel Mirasın ve Kültürel Bellek Kurumlarının Yönetimi Kongresi-İstanbul/Davetli Bildiri.

Yeşilbursa C.C. (2011). Sosyal Bilgilerde Miras Eğitiminin Öğrencilerin Somut Kültürel Mirasa Karş1 Tutumlarına ve Akademik Başarılarına Etkisi. Yayınlanmamış Doktora Tezi. Gazi Üniversitesi. Eğitim Bilimleri Enstitüsü.

Yıldırım, A., Şimşek, H. (2006). Sosyal Bilimlerde Nitel Araştırma Yöntemleri. Ankara: Seçkin Yayıncılık.

Yeşilkaya NG. (1999). Halkevleri: İdeoloji ve Mimarlık. İstanbul: İletişim Yayınları.

Yy. (1933, 7 Mayıs). Stadyom ve Yarış Yeri Bu Sene Yapılacak: Bunun İçin Bir Milyon Lira Hazır. Hakimiyet-i Milliye Gazetesi, 1.

Yy. (1933,14 Haziran). Yarış Yeri ve Stadyom Projeleri Tetkik Edildi: Jüri Heyeti Bugün Yarın Kararını Verecek. Hakimiyet-i Milliye Gazetesi, 1

Yy. (1933, 15 Temmuz). Dünyanın en güzel stadına biz sahip olacă̆ız. Türkspor Dergisi. 4(42-197),5.

Yy. (1934, 11 Ağustos). Yıllık Vakit yüzme müsabakaları. İspor Postas1. 1(18), 8

Yy. (1936, 23 Mart). Ankara Hipodrom ve Stadyomu: ilk kısım bitirildi. Ulus Gazetesi, 6.

Yy. (1936, 13 Temmuz). Cumhuriyetin gençliğe armağanı: yeni Ankara stadyomu. Türkspor Kurumu Dergisi. 3, 6-7.

Yy. (1936, 14 Aralık). Ankarada Stadyomun Açılma Hazırlıkları. Türkspor Kurumu Dergisi. 24, 3. 
Yy. (1936, 14 Aralık).Inönü Hükümetinin sporcu gençliğe büyük hediyesi: Ankara Stadyomu balkanlarda ve avrupanın birçok şehirlerinde dahi olmıyan bir eserdir. Türkspor Kurumu Dergisi. 24, 8-9.

Yy. (1936, 21 Birincikanun). Ankarada memleketin en modern stadı açıldı. İspor Postası. 3(141), 6-11.

Yy. (1936, 21 Aralık). Türk spor tarihinin en şerefli günü: 15 İlkkanun 1936. Başbakan İsmet Inönü Ankara Stadyomunu Değerli Nutukları ile açtılar. Türk Spor Kurumu Dergisi. 25, 7-8.

Yy. (1936, 21 Aralı). Stadyomun Açılışı Münasebetile Büyüklerimizin İntibaları. Türkspor Kurumu Dergisi. 25, 12.

Yy. (1936, 21 Aralık). Seviniyoruz.. türkiyemizin ilk modern stadı Başbakan tarafindan güzel bir nutuk ve uğurlu bir vuruşla maçlara açıldı. Top Dergisi. 3(39-112),4.

Yy. (1938, 20 Mayıs). Atatürkün yüksek huzurlarile yapılan spor ve gençlik bayramı. Ulus Gazetesi, 6.

http://t24.com.tr/haber/19-mayis-stadinin-yikimi-basladi,670735 (Erişim tarihi: 5 Temmuz 2018).

https://www.ahaber.com.tr/gundem/2018/06/02/ankarada-19-mayis-stadina-dev-mitingle-veda (Erişim tarihi: 8 Temmuz 2018)

http://www.cumhuriyet.com.tr/haber/spor/704293/Ankara_ya_yeni_stadyum_yapiliyor.html (Erişim tarihi: 2 Temmuz 2018).

https://www.dha.com.tr/foto-galeri/tarihi-stadin-yikim-calismalari-basladi/haber-1590112/p-5 (Erişim tarihi: 2 Temmuz 2018).

http://www.hurriyet.com.tr/efsane-19-mayis-stadinin-yikimi-basladi-40899181 (Erişim tarihi: 5 Temmuz 2018).

https://www.ibb.istanbul/News/Detail/27538 (Erişim tarihi: 5 Aralık 2018)

http://www.mimarlarodasiankara.org/?Did=9616\&utm_source=dlvr.it\&utm_medium=facebook (Erişim tarihi: 2 Temmuz 2018).

http://www.mimarlarodasiankara.org/index.php?Did=9062 (Erişim tarihi: 2 Temmuz 2018).

http://www.milliyet.com.tr/efsane-stadin-yikimi-basladi--mke-ankaragucu-2707745-skorerhaber/ (Erişim tarihi: 5 Temmuz 2018). 